REVISTAS DE LA FAHCE

Faculad de Humuridads y Cenois de lo Educaoion I UMY

? ?
Educación Física y Ciencia

ISSN: 1514-0105

ISSN: 2314-2561

revistaefyc@fahce.unlp.edu.ar

Universidad Nacional de La Plata

Argentina

\title{
Historia da obesidades: "O ventre de Paris" (1873), de Zola
}

Barbosa Santolin, Cezar

Historia da obesidades: "O ventre de Paris" (1873), de Zola

Educación Física y Ciencia, vol. 22, núm. 1, 2020

Universidad Nacional de La Plata, Argentina

Disponible en: http://www.redalyc.org/articulo.oa?id=439963095007

DOI: https://doi.org/10.24215/23142561e115

Esta obra está bajo una Licencia Creative Commons Atribución-NoComercial-Compartirlgual 4.0 Internacional. 


\section{Historia da obesidades: "O ventre de Paris" (1873), de Zola}

\author{
History og obesity: "The belly of Paris" (1973) de Zola \\ Cezar Barbosa Santolin \\ Universidade Federal do Mato Grosso do Sul - Campus \\ Pantanal, Brasil \\ cezarsantolin@hotmail.com
}

DOI: https://doi.org/10.24215/23142561e115

Redalyc: http://www.redalyc.org/articulo.oa? id $=439963095007$

Recepción: 07 Diciembre 2018 Aprobación: 13 Diciembre 2019

\section{Resumo:}

O presente artigo consistiu na análise da obra "O ventre de Paris" (1873), de Emílio Zola, publicada no final do Século XIX. O material possui valor enquanto fonte histórica primária do período de ressignificação da obesidade, contribuindo para a complementação de uma história sociocultural da obesidade. A metodologia consistiu na leitura do texto em busca de trechos que se referissem à condição investigada, seguida da extração e transcrição, complementada de análises e interpretações, visando destacar alguns aspectos presentes no texto. Com as análises, constatou-se uma ambivalência valorativa em relação à corpulência, à gordura corporal e à obesidade, assim como em relação às associações éticas, estéticas, culturais, morais, políticas e sociais. Por fim, entendeu-se que o objetivo da obra consistiu na tentativa de vincular a condição ressignificada negativamente à certas concepções político-ideológicas do próprio autor.

Palavras-Chave: Obesidade, História, Literatura.

\section{AbStract:}

This article analysed "The Belly of Paris" (1873), of Emile Zola, published in the late nineteenth century. The material is a primary historical source of the obesity resignification period, contributing to the sociocultural history of obesity. The methodology consisted of reading the text in search of passages that referred to the condition, followed by extraction and transcription, and complete analysis and interpretation, which aim to highlight some aspects in the text. With the analysis, there was one evaluative ambivalence toward corpulence, the body fat and obesity, as well as the ethical, aesthetic, cultural, moral, political and social associations. Finally, it was understood that the purpose of the work was an attempt to link the resignified condition negatively to certain political and ideological conceptions of the author.

KEYWORDS: Obesity, History, Literature.

\section{INTRODUÇÃO}

Há pouco mais de dois séculos, houve uma ressignificação da condição denominada corpulência no Ocidente. De uma questão até então tida como estética e/ou moral, aquilo que viria a ser denominado, posteriormente, como obesidade tornou-se uma condição médica, através de um discurso medicalizado ou patologizante (Foucault, 2001; Vigarello, 2012; Santolin, 2012; Santolin \& Rigo, 2015).

Ainda que na narrativa histórica de alguns autores, como Bray (2009) e Repetto (1998), a emergência dessa abordagem medicalizada da obesidade se situe em eras anteriores, historiografias mais rigorosas, com maior aporte de fontes, tal como a de Vigarello (2012), tem evidenciado e reforçado o argumento exposto em pesquisa realizada por Santolin (2012).

Neste sentido, com o intuito de agregar maior fundamentação empírica na constituição de uma história cultural da obesidade baseada em evidências a partir da interpretação de fontes primárias e contribuir, assim, para uma compreensão da historicidade do tema na Educação Física, o presente estudo objetivou analisar a obra literária "O ventre de Paris" (1956), do francês Emílio Zola ${ }^{1}$, publicada em 1873. Ressalta-se que a literatura, como neste caso, também pode ser constituída como uma fonte histórica primária relevante para os estudos socioculturais. 
Como exposto na dissertação e nos artigos sobre o tema por Santolin (2012) e Santolin e Rigo (2015), assim como no estudo de Vigarello (2012), os períodos entre o final do Século XVIII e meados do XIX foram muito relevantes para o processo de ressignificação da corpulência e da gordura corporal excessiva, sobretudo na Inglaterra e na França, país de origem de Zola. Desse modo, a obra em questão pode ser caracterizada como uma importante peça do quebra cabeça - sempre lacunar - de reconstituição dos acontecimentos do passado.

\section{Metodologia}

Metodologicamente, o primeiro procedimento consistiu na aquisição e leitura da versão traduzida para o português e publicada pela Editora Cia. Brasil, no ano de $1956^{2}$. Após o fichamento do texto, destacando os trechos considerados relevantes para o tema da corpulência e/ou da obesidade, buscou-se realizar uma análise do discurso (Bardin, 2011), no sentido da análise discursiva da enunciação, à guisa de Foucault (2008), ressaltando as vinculações conceituais estabelecidas com a temática, o que também pode ser denominado hermenêutica, já que consiste na interpretação dos significados atribuídos aos conceitos e categorias temáticas. Houve necessidade, também, de pesquisas adjacentes, em fontes históricas secundárias, sobre o autor, sobre o período histórico, sobre a obra, entre outros, para cumprir o princípio metodológico das pesquisas históricas denominado Regra do Contexto, conforme postula Struna (2007).

Optou-se pela transcrição integral das passagens de interesse para permitir a outros pesquisadores e demais leitores acesso ao material original de modo que possam julgar por si mesmos as interpretaçóes empreendidas, e, assim, atender, minimamente, ao princípio científico da validação intersubjetiva ou objetividade também nas pesquisas da área de humanas, permitindo a contestação e contraposições interpretativas que, porventura, outros pesquisadores possam vir a ter (Thomas, Nelson \& Silverman, 2007).

Ressalta-se que o uso de termos como gordo(a) ou corpulento(a) não encerram preconceitos em si, sendo utilizados nas análises e interpretações a partir de cuidados históricos-conceituais específicos, de modo a evitar anacronismos, tal qual exposto em Santolin (2012).

\section{Resultados E Discussão}

A obra "O ventre de Paris" (1956), do francês Emílio Zola, publicada em 1873, situa-se num período histórico de cerca de 20 anos antes da publicação, ou seja, por volta de 1853, e é ambientada, como o próprio título indica, na capital da França. O título da obra se remete, ainda, metaforicamente, ao Mercado de $\mathrm{Halles}^{3}$, em Paris, mencionado no texto apenas como "os Mercados":

“(...) os Mercados, quadrados, uniformes, aparecem como uma máquina moderna, desmesuradamente gritante, como uma enorme máquina a vapor, uma caldeira destinada a digestão de um povo, ventre gigantesco de metal, feito de madeira, cavilhado, rebitado, de vidro e de ferro fundido, de uma elegância e de uma potência de motor mecânico, funcionando com o calor da fornalha, a vertigem, o impulso ciclópico das rodas" (Zola, 1956, p. 32)

O fato de Zola não especificar que se trata do Mercado de Halles e utilizar o termo no plural, assim como em outras passagens do texto, sugerem que o autor desejava se referir a uma concepção de mercado mais ampla, enquanto atividade comercial. Assim, tanto Halles quanto “os Mercados" são o ventre de Paris, sendo ambos retratados criticamente pelo francês, como se pode perceber na passagem supratranscrita. Permanece, entretanto, como se poderá ver no decorrer das análises, uma certa ambiguidade no juízo do autor ao longo da obra.

Apesar disso, o romance pode ser classificado como político, já que tem como tema central o planejamento de uma revolução comunista, que será frustrada pelos citadinos que compõem "os Mercados”. Pode-se identificar uma abordagem classista, crítica aos valores considerados burgueses, além de panfletária da causa 
socialista, tal qual no outro romance mais conhecido do autor, Germinal, de 1885, adaptado para o cinema em 1993 pelo diretor Claude Berri.

Tal enfoque anticapitalista, com matizes românticas, anti urbana, anti civilizatória, etc. deita raízes tão fundas quanto o próprio sistema capitalista, sendo difícil traçar e reconstituir suas origens. Apesar disso, representantes mais recentes e quase-contemporâneos de Zola podem ser identificados, como, por exemplo, Jean Jacques Rousseau. Neste sentido, ao melhor estilo rousseauniano, Zola escreve que "as grandes cidades não prestam para nada; aqui [no campo] é que os senhores deveriam passar a vossa vida” (p.233).

Há, entretanto, um outro protagonista além dos Mercados: Florêncio. Na narrativa, retratado como um homem bom, moral, injustiçado pelo destino, que, a princípio, lhe fez órfão de pai, e, posteriormente, também de mãe. Acrescido da incumbência de cuidar de um irmão mais novo, tivera que abandonar o curso de direito e começar a trabalhar como professor para sustentar o irmão.

Desde o início da narrativa biográfica, a personagem é apresentada como plenamente boa, disposta a sacrifícios, virtuosa e moral. Mesmo quando rouba uma cenoura, no início da história, é somente para não morrer de fome. Por isso, "se fez republicano; entrou na república, como as moças perdidas entram desesperadas num convento" (p.51). Cultivou utopias de "justiça e de verdade absolutas" (p.51) e

“tornou-se um daqueles oradores inflamados que preparam a revolução como uma religião nova, toda de esperança e de redenção. Foram precisas as jornadas de dezembro ${ }^{4}$ para o arrancarem de sua ternura universal. Estava inerme. Deixou-se apanhar como cordeiro e foi tratado como lobo. Quando acordou do seu sermão de fraternidade, rebentava de fome na laje fria de uma casamata ${ }^{5}$ de Bicetre" $^{6}$ (p.52).

Confundido com revolucionários, ao passar próximo de uma barricada, Florêncio é mantido preso por um determinado tempo não especificado pelo autor. Após isso, liberto, retorna à Paris, sendo encontrado, inconsciente, deitado no meio da rua, sem que o romancista dê maiores detalhes sobre os acontecimentos durante a reclusão ou que levaram o protagonista a tal situação. Quem encontra-o é uma tal senhora François, que o considerou "magro como uma vara" e "o julgou morto" (Zola, 1956, p. 6). "Apiedada decerto pela sua extrema magreza" (id, p.17), o homem apresentava-se para ela "digno de dó", "deixando ver a magreza dos ossos" (id, p.7).

Após ter sido preso, Florêncio teria passado a sentir fome: "Fora desde esse dia que ele começara a sofrer fome; sentira-a na casa-mata, e nunca mais o abandonara a fome” (id, p.15). Por consequência,

“a fome nunca mais o deixara. Ele bem investigava nas suas recordações, não se relembrava de uma hora de fartura. Tornarase seco, encolhera-se lhe o estômago, trazia a pele colada aos ossos. E vinha encontrar Paris, gordo, anafado, soberbo, extravasando de alimentação no fundo das trevas; era sobre um leito de legumes que ele penetrava na grande cidade: rolava num meio desconhecido de comestíveis, que sentia exuberar em volta dele e que o inquietava” (id, p.16)

Florêncio passa, portanto, de uma situação miserável, preso, exilado numa ilha, para uma outra opulenta. Apesar disso, no começo, convive com aquela abundância de comida sem poder pegá-la, esfomeado, tendo que conviver com "tentações sobre-humanas" (p.33) naquele "sonho intolerável de alimentos gigantescos pelos quais se sentia perseguido" (p. 35). "Estava embriagado de miséria, de fome” (p.38), “(...) o estômago esmagado por tudo quanto vira, adivinhando novas e incessantes abundâncias de alimentos, pediu mercê e apoderou-se dele uma dor maluca de morrer assim de fome, na cidade de Paris abarrotada, naquele despertar fulgurante dos Mercados" (p.39), que "era uma fartura de coisas boas, de coisas saborosas, de coisas gordas" (p.42-3), "repletas de alegrias de gordura” (p.43) - uma verdadeira "capela consagrada à barriga" (p.43)

Assim, Zola introduz uma contraposição dual entre um sujeito protagonista virtuoso, moral, injustiçado, magro e faminto, contraposto à cidade e aos citadinos protagonistas: corruptos, corruptores, imorais, injustos, gordos e opulentos. Como defendido por Birnbaum (1979), o lema "o povo contra os gordos" teria sido explorado em discursos aos quais o autor denominou anti-nobres e populistas desde o período da Revolução Francesa. Algumas fontes encontradas por Santolin (2012) indicam que o mesmo teria ocorrido na Inglaterra 
com um viés político-partidário e classista, polarizando os tories (partido dos nobres) e os whigs (partido dos anti-nobres).

Através do personagem Cláudio, artista-pintor, Zola expressa o maior rancor contra os gordos-burgueses: "E sabe, meu amigo, o que enraivece, o que não acho justo, é que esses tratantes dos burgueses comam tudo isto!" (Zola, 1956, p.29). Assim como Florêncio, parece passar fome ao se queixar: "Encontra-se sempre alguém que nos paga de beber, mas não se encontra nunca ninguém que nos pague um prato de comida" (id, p.30). Se o seu rancor não é especificamente por este motivo, talvez seja por nunca ter sido "capaz de esboçar aquelas caras redondas, em que não aparecem osso" (p.92). Pode ser, ainda, por não conseguir uma pretendente "bela", já que demonstra apreciar tais dotes:

"Hem! Que belos lombos, tanto ele como ela! - acentuava Cláudio falando notadamente de Marjolin possuído de admiração e de cobiça - E dizer por aí que um animal daquele é feliz! ... Quando devorarem as batatas, vão se deitar juntos num dos cestos cheios de penas. Aquilo pelo menos é vida! Sinceramente, o senhor tem razão em se deixar ficar mesmo pela salsicharia; é bem possível que isso o faça engordar" (p.93)

Pode-se constatar, portanto, uma certa ambivalência do autor em relação à corpulência, à gordura corporal e a comer. Por um lado, percebe-se um discurso crítico, raivoso, contra os corpulentos, gordos e comilóes, considerados politicamente burgueses; por outo lado, entretanto, deixa-se transparecer um certo ressentimento ou inveja por não ter tanto para comer, assim como uma valoração positiva da corpulência e da gordura corporal, retratados como sinal de beleza.

Antes da ressignificação da beleza da corpulência e da gordura corporal, não somente era considerado belo, como os critérios quantitativos, ainda que visuais, eram distintos dos atuais. Quando Florêncio vê sua cunhada pela primeira vez, por exemplo, observa que ela "tomava a largura da porta, não sendo, contudo, demasiado gorda, colo forte, na maturação dos trinta anos" (p.43). Portanto, diferentemente da atualidade, ter a largura de uma porta não era considerado ser gorda.

Já Quenu, o irmão de Florêncio, também “reparou na magreza, na miséria do irmão” (p.45), enquanto este constatou que Quenu

"efetivamente estava gordo, gordo demais para os seus trinta anos. Transbordava na sua camisa, no seu avental, nas suas roupas brancas, que o vestiam como se fosse um boneco enorme. A sua face rapada alongara-se, tomara, com o tempo, uma longínqua semelhança com o focinho daqueles porcos, daquela carne, em que as suas mãos mergulhavam e revolviam o dia inteiro" (p.45)

Apesar da infâmia desta comparação, de um gordo com um porco, trata-se de metáfora antiga, que data do medieval, em que o glutão era representado cavalgando um porco (Vigarello, 2012; Quellier, 2011). Dando continuidade, Zola ressalta que "todos respiravam saúde; estavam soberbos, quadrados, luzidios; olhavam-no com o susto das pessoas muito gordas, tomadas de vaga inquietação em frente de uma pessoa magra" (Zola, 1956, p.45). Aqui, ressalta-se que, ainda na época, ser gordo não era simplesmente uma questão de beleza, mas era sinônimo de ser saudável.

Apesar de restabelecer a alimentação após ir morar na casa do irmão, "Florêncio continuava magro" (p.48) e Lisa constatava: "interessante: você agora come bem e mesmo assim, não engorda de modo algum... Não lhe aproveita o que come" (p.164). Mesmo assim, o magro foi "deixando que corressem os dias no meio daquele ambiente gorduroso, daquela prosperidade” (p.62). "À mesa, Quenu enchia-o de comida, irritou-se por ser ele pouco comedor e por deixar nos pratos metade das comidas com que lhe enchia o prato” (p.67-8). Já “o descaso daquele homem magro perturbava-a; sentia por ele uma espécie de respeito, mesclado de um receio vago" (p.68) eram os sentimentos de Lisa.

"A cunhada nunca passara por carências:

Mas Lisa tornou a perguntar se era possível ficar-se três dias sem comer. Era já isso concebível! - Não! Disse ela - Eu não posso acreditar nessa ... além do mais, não pode ninguém resistir três dias sem comer. Quando se diz que: 'Aquele está 
a morrer de fome' é uma maneira de falar. Come-se alguma coisa, seja lá o que for ... é preciso que sejam uns desgraçados, repelidos por todos, gente perdida...” (p.103)

E mantém sua opinião negativa de Florêncio: "um homem capaz de permanecer três dias sem comer era para ela um ser humano absolutamente perigoso. Porque, afinal de contas, pessoas honestas jamais se veem em situações tão deprimentes" (p.103).

Com o tempo,

“achava Florêncio importuno; tinha consciência da maneira incompreendida porque viera a cair no meio daquele mundaréu de gente gorda, ele que era um ingênuo magricela; confessava abertamente que viera pôr em desorganização todo o bairro, que se tornava um embaraço para os Quenu, um primo de contrabando, de feições demasiadamente comprometedoras" (p.91).

Todas essas desconfianças em relação à magreza e aos magros, de que são perigosos, desonestos, etc., não eram incomuns em épocas anteriores às ressignificações estéticas, morais, religiosas e médicas da corpulência e da obesidade que começaram a ocorrer a partir do Renascimento (Santolin, 2012; Vigarello, 2012).

Apesar disso, ficava-se e "resvalava para a covardia feliz daquela digestão saudável, naquele ambiente engordurado em que vivia havia quinze dias. Eram a flor da pele, inúmeros pruridos de gordura nascente, uma lentidão invasora do ser inteiro, uma doçura macia de pessoa estabelecida" (Zola, 1956, p.109).

Augusto, um dos funcionários da salsicharia, era "gorducho, mas de uma gordura feia" (p.68). Zola não explica o que seria considerado uma gordura feia, mas, subjacente ao comentário, está implícito a ideia de que havia uma gordura que era considerada bonita. Tal fato confirma-se pela apresentação da "bela Lisa" e da "formosa normanda" como as mulheres consideradas mais belas nos Mercados e ambas retratadas como corpulentas, gordas, em várias passagens. Também "Gavard detestava as mulheres magricelas. Dizia que lhe causava má impressão sentir os ossos debaixo da pele” (p.73).

Ainda que as rivais serem ambas corpulentas, referiam-se uma a outra pejorativamente como “gorda” (p.238), "banha” (p.89), "gorducha” (p.89), "gordalhona” (p.132).

Marjolin também apreciava a corpulência de Lisa: "Achava-a tão encantadora, tão cheia, tão redonda, que lhe causava um bem contemplando-a. Experimentava diante dela uma plenitude como quando comida ou bebia alguma coisa muito saborosa" (p.213). Aos olhos de Cláudio, entretanto, eram "carnes duvidosas, preparadas para se exibirem” (p.234), as belas moças dos Mercados. Tanto pela associação a beleza quanto pela associação a saúde, havia o medo de emagrecer: "Minha tia não faz bem por se ocupar destas histórias porque emagrecem" (p.90).

Isso não impede, entretanto, que Zola, ao colocar sua opinião nas entrelinhas dos pensamentos de Florêncio ao observar Lisa, julgue aquele padrão estético de maneira distinta, primeiro elogiando-o, para, em seguida, compará-lo aos porcos:

\footnotetext{
"Naquele dia estava ela de uma jovialidade soberba; a alvura do avental e das mangas continuava a brancura dos pratos até ao seu pescoço gordo, as suas faces coradas, onde sobressaiam os tons baços dos presuntos e a palidez das banhas translúcidas. Atemorizado a ponto que fitava-a, inquieto por aquele apresentação cavalheiresca, Florêncio terminou por examiná-la sorrateiramente, nos espelhos em volta da loja. Lisa era refletida nele de frente, de costas, de lado; mesmo no teto a estava vendo refletida de cabeça para baixo, com o seu penteado, os seus pequenos bandos ligados as fontes. Era toda uma multidão de Lisas, mostrando a largura dos ombros, a conjuntura opulenta dos braços, o peito ondulado, tão mudo e tão protuberante, que não acordava pensamento algum carnal e que se parecia com um abdome. Deteve-se, demorando-se principalmente num dos seus perfis, que se refletia num espelho, ao seu lado, entre duas bandas de porco. Ao longo dos espelhos e dos mármores suspensos pelos ganchos dos varóes, pendiam porcos e mantas de toucinho para picar; e o perfil de Lisa, com o seu avantajado pescoço, as suas linhas arredondadas, o seu colo adiantava, punha uma aparência de rainha empastada, no meio daquele toucinho e daquelas carnes cruas" (p.76)
}

Noutro momento, Lisa é também comparada a uma vaca (p.109) - adjetivos e comparações nada lisonjeiras. 
Outras associações são feitas com a corpulência: "Marjolin, aos dezoito anos, tinha já a predisposição para ventrudo, de um homem gorducho, uma inteligência que era uma nulidade, vivendo pelos sentimentos" (p.198). Não se trata de associação nova entre a gordura, a corpulência, o ventre grande e a estupidez, a ignorância, a ingenuidade, etc. (Vigarello, 2012). Não só associações valorativas negativas são apresentadas, mas também valorações positivas, como "tão gordo, tão jovial” (p.292).

Quando oferecem um emprego como inspetor nos Mercados para Florêncio, ele, a princípio, nega - "Jurei não aceitar nada do império. Prefiro morrer de fome do que trabalhar para a prefeitura” (p.79) - porém depois acaba por aceitar. As comerciantes, entretanto, não se dão bem com o novo instrutor e começam a criar constrangimentos para ele, que percebe "aquele estraçalhamento de mulheres enormes, de ventres e de agressivos colos gritando numa alegria gigante, quando ele era vítima de alguma armadilha. Os rostos vertendo sangue e suor encaravam-no. Nas inflexões canalhas das vozes, nos quadris opulentos, nos pescoços inchados, no bambolear das coxas, nos trejeitos das mãos, ostentava toda uma onda de imundícies a ele dirigidas” (p.134).

De fato, "desde o dia em que chegou [em Paris], tudo havia piorado; ele é que havia comprometido, que irritava, e perturbava aquele povo que até então vivera numa tão bem nutrida paz” (p.163-4).

Por fim, acaba por afirmar sua autoridade enquanto inspetor perante as comerciantes, mas "o sonho extravasava-se lhe, ficando a arquitetar estufas colossais, cubas imundas de esfolador de animais em que era derretida a banha má de um povo" (p.149).

Quando Florêncio acaba por retomar à política, Zola retrata esta atitude como uma reação, na qual o protagonista estaria sendo impelido por querer vingar-se contra as injustiças que teria sofrido:

"Finalmente, Florêncio retomou a política. Sofrera muito pela política, a fim de que ela não viesse se tornar sua ocupação principal da sua vida. Se não fora o meio ambiente e as circunstancias, ele contentar-se-ia em ser um bom professor de província, desfrutando a paz da sua modesta cidade. Mas havia sido tratado como lobo, encontrando-se agora como que marcado pelo desterro para ser um elemento de combate. O seu mal-estar neurótico não era outra coisa além do despertar dos seus prolongados êxtases de Caiena, das suas aflições em face das torturas imerecidas, dos seus propósitos de vingar ainda a humanidade tratada a chicote e a justiça calcada a pés. Os Mercados colossais, os alimentos exuberantes e forte haviam acelerado a crise. Pareciam-se lhe o animal satisfeito e a mastigar. Paris de tripa e tudo, digerindo a sua gordura, apoiando cegamente o império. Punham em derredor dele colos imensos, rins disformes, rostos redondos como argumento continuados contra a sua magreza de mártir, o seu rosto pálido de descontentamento. Era o ventre do comerciante, o ventre de média honestidade, abastecendo feliz, luzido ao Sol, achando que tudo ia às mil maravilhas, que nunca as pessoas de hábitos moderados haviam engordado tão excelentemente. Então, viu-se de punhos juntos, pronto para entrar em luta, mais nervoso pela recordação do seu exílio do que se encontrara quando retornara a França” (p.152).

Assim, como exposto na tese de Birnbaum (1979) sobre o período da Revolução Francesa, Zola retoma o maniqueísmo populista em torno da corporeidade de supostas classes sociais - dessa vez, entretanto, contrapondo o povo magro contra os burgueses gordos ao invés dos aristocratas gordos, como tinha sido há uns 100 anos antes, conforme análise daquele autor.

Em outra passagem, "julgando que precisava vingar a sua magreza contra aquela cidade de gordos, ao mesmo tempo que os defensores do direito morriam de fome no exílio, tornou-se justiceiro, julgou que seria seu dever, levantar-se mesmo dos Mercados” (Zola, 1956, p.244)

Zola afirma que Florêncio professava o socialismo (p.168), “um vermelho" (p.179), identificando tal ideologia como um ideal humanitário. A partir de alguns contatos, o protagonista se junta a um pequeno grupo político, que almeja realizar uma revolução. Acaba, também, por levar seu irmão Quenu, que, apesar de não entender nada de política, assimilava a doutrinação dos mais exaltados: "Quenu mesmo assim recordavase de uma frase de Charvet, o qual dizia que esses burgueses de borra, esses comerciantes obesos, oferecendo o seu amparo a um governo indigesto, deviam ser os primeiros a serem totalmente jogados as fossas. Era graças a eles, graças ao seu amor próprio a barriga, que o arbitrarismo se impunha e corroía uma nação” (p.181). Aqui se apresenta, explicitamente, uma ideologia que vai da situação socioeconômica enquanto formadora de 
identidades políticas à ancoragem no corpo da caracterização e caricaturização, com fins políticos, classistas e populistas.

A outras comerciantes, a magreza de Florêncio causa “pavor" (p.88), é pavoroso (p.132). Parece haver uma associação, no senso comum da época, entre magreza e maldade, já que é preciso diferenciar tais características para apaziguar o medo: “(...) é magro, mas não é mau homem” (p.88). Na opinião da mãe da Normanda, "ele possui um olhar falso (...) não acredito nas pessoas magras. Um homem magro é capaz de tudo. Não tenho conhecimento de um só que fosse bom... Aquele certamente que o ventre lhe fugiu para as nádegas; porque é chato como uma tábua" (p.157). E Lisa arrebata "Nem sequer pode melhorar a sua magreza o desgraçado, tão corroído está de maldade” (p.185).

Desconfiança da magreza, a ponto do próprio Florêncio desconfiar de si mesmo e acreditar em Lisa: "A razão estava com ela, decerto. Era tão sadia, tão serena, que não podia desejar senão o bem. Era ele, o magricela, o perfil negro suspeitado, que devia ser mau e pensar coisas inconfessáveis" (p.108). Possuía o "rosto sombrio de pária” (p.132).

Outras associações negativas presentes são que "os homens magros são homens nervosos” (p.89), malandros (p.277) e rancorosos (p.281). Porém, há também, ainda que raras, uma associação positiva: “estes homens magros são uns valentes" (p.326).

Após tanto maniqueísmo velado, Zola expõe, ao final da obra, explicitamente sua tese político-corporal através da personagem Cláudio, que explica a Florêncio:

"- Conhece a batalha dos Gordos e dos Magros? - indagou-lhe em seguida: Florêncio, surpreendeu-se e respondeu que não. Então Cláudio tornou-se entusiasmado e falou dessa série de estampas com muitos louvores. Enumerou vários episódios: os Gordos, imensos, a rebentarem, cuidando das glutonices da noite, ao passo que os Magros, curvados ao peso cotidiano dos jejuns olhavam para a rua, com uma cara de postes cobiçosos; acontece que, os Gordos, a mesa com suas enormes bochechas avermelhadas a expulsarem um Magro que tivera a petulância de se introduzir sorrateiramente, e que parece um palito pendido no meio de um povo de galinhas. E o que se compreendia nisso tudo era o drama humana; terminou dando a classificação dos homens em Magros e Gordos, dois grupos distintos e hostis, devorando-se um ao outro, tornando mais redondo o ventre e gozando.

- Certamente - afirmou ele - Caim foi Gordo e Abel um Magro. Desde que se verificou o primeiro assassínio, foram sempre as pavorosas fomes que chupavam o sangue dos pobres comedores... é uma permanente comilança do mais fraco pelo mais forte, cada um glutindo o vizinho amigo ao mesmo tempo sendo devorado por este. Tome nota disso, meu amigo, não confie nos Gordos. (...) Nós dois, meu amigo, somos Magros, compreende... Ora, diga-se, com ventres batidos, mirrados como os nossos, podemos ocupar muito lugar ao Sol? Florêncio fitou as duas sombras, sorrindo. Mas Cláudio irritava-se. Gritava: - Voce faz mal em achar graça nisto. Eu sofro por ser Magro. Se eu fosse um Gordo, poderia pintar sossegadamente, teria um maravilhoso atelier, venderia os meus quadros por bom preço. Em vez disso, sou um Magro, digo que extermino o meu temperamento de desejar encontrar coisas que nem ao menos abalam os Gordos. Por esse motivo, hei de morrer, estou certo disso, com a pele grudada nos ossos, tão chato que até me podem colocar depois no meio de duas folhas de um livro para me enterrarem... E voce, então? Voce é um Magro surpreendente, o rei dos Magros, juro. Recorda-se da sua briga com as peixeiras? Era fenomenal ver aqueles colos gigantescos a solta contra o seu peito deprimido; e faziam isto por instinto, perseguiam o Magro, como os gatos caçam os ratos... Em princípio, entende, um Gordo tem pavor de um Magro, tanto que experimenta a necessidade de o afastar de sua frente a dentada ou a pontapé. É por isso que, no seu lugar, eu tomaria as minhas precauções. Os Quenu são Gordos, as Méhudin são Gordas, enfim, voce só tem ao seu redor Gordos. Se fosse comigo, estaria preocupado. - E Gavard, e a Saget, e o seu amigo Marjolin? - indagou Florêncio que continuava sorrindo. - Oh! Se quer - retorquiu Cláudio - eu vou classificar-lhe todos os nossos conhecimentos. Há bastante tempo que eu tenho no meu atelier as cabeças de todos eles num cartão, com a indicação da ordem da qual eles fazem parte. É todo um capítulo de história natural... Gavard é um Gordo, mas um Gordo que tem a pretensão de ser Magro. A variedade é muito vulgar... A senhora Saget e a senhora Lecoeur são Magras, mas são variedades a qual devemos temer, Magros desesperados, capazes de tudo para engordarem... O meu amigo Marjolin, a Cadine, a Sarriete, três Gordos, ingênuos ainda, tendo as estimáveis fomes da mocidade. É preciso notar que o Gordo, enquanto não envelhece, é um ser encantador... O senhor Lebigre, um Gordo, não é assim? Quanto aos seus amigos políticos, são quase sempre Magros, Charvet, Clemencia, Logre, Lacaille. Só merece exceção esse grande estúpido do Alexandre e o sobrenatural Robine" (p.235-236)

E prosseguia com as especificações de sua classificação peculiar: 
"Logre era classificado como magro que trazia o abdome entre os dois ombros; a encantadora Lisa era toda ela uma espécie de abdome; e a formosa Normanda, toda busto; a Saget não aproveitara certamente, na vida uma ocasião para engordar, porque não tolera os Gordos, da mesma maneira que detesta e odeia os Magros; Gavard empenhava a sua gordura, tendo que acabar batido como um percevejo. (...) A senhora François, a senhora François... Não, não, positivamente ainda não cheguei a classifica-la... é uma excelente mulher, a senhora François, e nada mais posso dizer. Essa não está entre os Gordos nem entre os Magros. E pronto!" (p.236-7)

A filha de Lisa e Quenu - Paulina - “era muito gorda e não podia correr” (p.250), além de ser apresentada como ingênua ao ser maltratada facilmente por Muche, filho da peixeira do Mercado.

"Os [queijos] Roquefort, igualmente abrigados em campanulas de cristal, tinham ares de realeza, faces enceradas e gorduchas, com veias azuis e amarelas, como se estivessem sofrendo de uma enfermidade vergonhosa de pessoas abastadas por terem comido trufas demais" (p.262)

Ao fim, quando todos os comerciantes do Mercado se juntam para combater "o vermelho" (p.265), “iniciou-se então contra aquele moço magrela a guerra dos ventres enormes, dos colos abundantes” (p.279). "Os Mercados eram cúmplices” (p.334) da delação que viria a exilar novamente o conspirador magricela.

Cláudio, no fim, "criticava os gordos, dizia que eles haviam vencido. Ao seu redor não via senão gente gorda, arredondando-se, esborrachando-se de fartura, saudando um novo dia de bela digestão" (p.341). Já “a salsicharia respirava e inspirava novamente saúde, uma saúde gorda” (p.342).

\section{Conclusões}

O objetivo do presente artigo foi empreender a análise da obra "O ventre de Paris”, de Emílio Zola, enquanto fonte histórica primária, para preencher certas lacunas na história sociocultural da obesidade no Século XIX. A análise concentrou-se nas passagens em que haviam referências à obesidade, gordura, corpulência, dentre outros, prezando pela transcrição do material original acrescido de comentários que ressaltavam as associações destas condições com valores éticos, estéticos, culturais, morais, políticos e sociais.

Após as análises, pode-se constatar a existência de tais associações, retratando a corpulência, a gordura e a obesidade de maneira bastante ambivalente - algumas vezes como boa, bela, honesta, superior, etc., outras vezes como má, feia, desonesta, corrupta, inferior, etc. Essa ambivalência pode ser compreendida a partir da identificação do período em que foi produzida e publicada a obra como de popularização da ressignificação da condição, que passou a ser vista de modo negativo em todos os sentidos.

Percebe-se, a partir das análises, também, uma tentativa de Zola em vincular a condição, que emergia ressignificada negativamente na história sociocultural ocidental, à objetivos políticos, a saber, a causa comunista/socialista, de modo a denegrir a imagem daqueles que o autor via como inimigos, ou seja, "os burgueses" e a "burguesia”. Assim, almejava garantir restritamente os atributos valorados positivamente à uma suposta classe proletária, à qual Zola se dizia identificado, assim como a ideologia que se proclama defensora de seus membros.

Depreende-se, portanto, das análises do material empírico a constituição do seguinte enunciado: os burgueses são gordos. A expressão "burguês”, neste caso, deve ser compreendida numa acepção ideológica do marxismo (Marx \& Engels, 1848)

Por fim, enquanto fonte histórica, a obra tem seu valor e merece ser incluída dentre as peças do quebra-cabeça de uma história sociocultural da obesidade no Ocidente, já que permite uma ampliação do entendimento do período crucial que foi a ressignificação valorativa desta condição.

\section{REFERÊNCIAS}

Baecque, A. (1989). Le discours anti-noble (1787-1792) aux origines d'un slogan: "Le peuple contre les gros". Revue d'Histoire Moderne et Contemporaine, 36(1), 3-28. 
Bardin, L. (2011). A análise da enunciação. Em: Bardin, L. Análise de conteúdo. Quarta parte. Cap. III. Portugal: Edições 70, 169-184.

Birnbaum, P. (1979). Le peuple et les gros. Paris: Grasset \& Frasquelle.

Bray, G. A. (2009). History of obesity. In: Williams, G.; Frühbeck, G. Obesity: science to practice. Chicester: WileyBlackwell.

Foucault, M. (2001). Os anormais: curso no Collège de France (1974-1975) (7ª ed.) São Paulo: Martins Fontes.

Foucault, M. (2008). A arqueologia do saber. ( $\left.7^{\mathrm{a}} \mathrm{ed}\right)$. Rio de Janeiro: Forense Universitária.

Marx, K., \& Engels, F. (1848). O manifesto do partido comunista. Disponível em: http://www.ebooksbrasil.org/ado beebook/manifestocomunista.pdf. Recuperado em 08 de Junho de 2018.

Portal Domínio Público. (2018). Disponível em: http://www.dominiopublico.gov.br/pesquisa/DetalheObraForm.d o?select_action=\&co_obra=37109. Recuperado em 19 de Agosto de 2018.

Quellier, F. (2011). Gula - história de um pecado capital. São Paulo: SENAC.

Repetto, G. (1998). Histórico da obesidade. In: Halpern, A, Godoy MA, Suplicy HL, Mancini C, Zanella MT. Obesidade. São Paulo: Lemos.

Santolin, C. B. (2012). O nascimento da obesidade: um estudo genealógico do discurso patologizante. (Dissertação de mestrado). Pelotas, RS. Universidade Federal de Pelotas (UFPel).

Santolin, C. B., \& Rigo, L. C. (2012). Por que o termo "gordo" se tornou politicamente incorreto no Brasil? Anais do VI Congresso SulBrasileiro de Ciências do Esporte. Rio Grande (RS). Disponível em: http://cbce.tempsite.ws/con gressos/index.php/6csbce/sul2012/trackDirector/index/submissionsAccepted . Recuperado em: 19/07/2016.

Santolin, C. B., e Rigo, L. C. (2015). O nascimento do discurso patologizante da obesidade. Movimento, 21(1), 81-94

Struna, N. L. (2007). Pesquisa histórica em atividade física. Em: Thomas, J. R., Nelson, J. K., \& Silverman, S. J. Métodos de pesquisa em atividadefísica ( $\left.5^{\mathrm{a}} \mathrm{ed}\right)$. Cap. 12. Porto Alegre: Artmed, 189-201.

Thomas, J. R., Nelson, J. K., \& Silverman, S. J. (2007). Métodos de pesquisa em atividade física ( $5^{\mathrm{a}} \mathrm{ed}$.) Porto Alegre: Artmed.

Vigarello, G. (2012). As metamorfoses do gordo. Rio de Janeiro: Vozes.

Zola, E. (1956). O ventre de Paris. São Paulo: Cia. Brasil.

\section{Notas}

1 Émile Zola (1840-1902), foi um escritor e jornalista francês, sempre envolvido com várias das causas políticas de seu tempo.

2 A obra original, escrita em francês, já se encontra em domínio público, por ter sido publicada originalmente em 1873, podendo ser acessada através do Portal Domínio Público (2018).

3 O Mercado de Halles não é como um supermercado, fechado unicamente, mas como uma feira ao ar livre, porém com algumas construções. Existe há pelo menos três séculos até a atualidade, passando por diversas revitalizações, reformulações e melhorias.

4 A referência é ao golpe de estado de 2 de Dezembro de 1851 empreendido por Luís Napoleão Bonaparte, sobrinho de Napoleão Bonaparte.

5 Casamatas são instalações militares fortificadas, como bunkers. No romance, a palavra foi empregada com significado de prisão.

6 Referência a uma região ou instituição na França.

\section{BY-NC-SA}

